8-2013

\title{
Advance directives: A policy required in the Asian countries
}

Nasreen Panjwani

Aga Khan University, nasreen.panjwani@aku.edu

Follow this and additional works at: https://ecommons.aku.edu/pakistan_fhs_son

Part of the Nursing Midwifery Commons

\section{Recommended Citation}

Panjwani, N. (2013). Advance directives: A policy required in the Asian countries. i-manager's Journal on Nursing, 3(3), 30-33.

Available at: https://ecommons.aku.edu/pakistan_fhs_son/295 


\title{
ADVANCE DIRECTIVES: A POLICY REQUIRED IN THE ASIAN COUNTRIES
}

\author{
By \\ NASREEN PANJWANI \\ MScN Student, Aga Khan University School of Nursing.
}

\begin{abstract}
Advancements in health care have resulted in elaborate treatments all over the world and contributed to problems at times for the terminally ill who need palliative care. Futile treatments have demonstrated to defuse the symptoms of the disease without curing. In such scenarios physicians only prolong life of patients, keeping them away from dying peacefully and depriving them from quality of life. In this context, families exhaust their financial and material resources for the treatment of their loved ones without any substantial results. Health care systems are passionate about prolonging life and are ignoring the component of caring by disregarding the patient's rights. There are no existing policies about Advance Directives (ADs) in Pakistan and many other Asian countries, which result in ethical dilemmas among nurses and physicians. Thus, the decisions to limit the treatments such as ADs are needed in this age of modern medical technology. In this paper the author walks the audience through a scenario where she felt a dire necessity for a policy of ADs in an Asian country like Pakistan. This position paper reveals the ethical dilemma that is encountered, the position taken, supported by the ethical principles, the arguments, counter arguments and the justification for having the policy of ADs.
\end{abstract} Lastly, the final position has been stated and recommendations to implement the policy have been elaborated.

Keywords: Advance Directives, Living Will, Ethical Dilemma, Autonomy, Ethics of Care, Terminally ill, Palliative, and Quality of Life.

\section{INTRODUCTION}

In a Special Care Unit, a sixty-five year old female, admitted with Gastro Intestinal Bleed, a known case of lung Sarcoidosis and mitral valve replacement. She was on continuous Oxygen therapy and overnight BIPAP for 6 months for mechanical removal of Carbon dioxide. During hospitalization she developed Pneumonia. She was tired of elaborate treatments and expressed her will to the family and primary physician that she not be given any aggressive treatments. In the hospital there was no policy for a living will. Her prognosis was not good; the doctor had written orders for DNR (Do Not Resuscitate) after discussing with the family, but the son expressed his desire to "Do Everything Possible" other than resuscitation, even after knowing the patient's wishes. She was put on continuous BIPAP as she developed $\mathrm{CO}_{2}$ Narcosis. She then went into renal shut down and Haemodialysis was unsuccessful due to severe hypotension. She developed bedsores, became oedematous and fluid started oozing from her limbs. Concurrently, she became unresponsive. After 20 days,
BIPAP was discontinued, and the patient expired within an hour. She was my "MOTHER" and I saw her in that misery, it was really difficult for me to see her agony.

Analysis of the Ethical Dilemma

The Ethical Dilemma is patient's autonomy versus the ethics of care. The patient was not in favour of vigorous treatments as her condition was not improving, but the loved ones demanded to do everything possible. For the son, it seemed difficult to see his mother suddenly go, when he hoped she would improve with the medical advancements available today. Being a nurse, the daughter envisages that her mother would not recover and suffer even more, but could not convince her brother to withhold treatment. She asks today that "why did my mother suffer when she had already expressed her will"? Who should decide for advance treatments? The ethical dilemma is the Patient's Autonomy versus the Ethics of care. The patient's autonomy was neglected and treatments to prolong life, such as use of BIPAP round the clock and dialysis were implemented. The family dreaded the loss of their loved one and insisted that 
treatments be continued. We as health professionals agree that use of extraordinary technology should be withheld in favour of death with dignity.

\section{Identification of the Position}

If there would have been the concept of advance directives in Pakistan, things would have been different. Patients would not suffer and even the loved ones would not go through a guilt trip by respecting patient's autonomy. Introduction of the concept of Advance Directive Document seems really important in this age of modern medical technology in the Asian countries. Advance Directives include legal documents such as the living will, power of attorney option and surrogate decision making (Burkhardt \& Nathaniel, 2002). It is a legal document which provides information to the care providers about the patient's wishes regarding advance treatment options for the future when decision making would not be possible for the incompetent patient. Everyday observations reveal that death is being delayed with futile treatments and gadgets like ventilators, BIPAPS, etc., instead of making it peaceful (Akhtar, 2010). Initially, the concept of a living will would not gain acceptance in family oriented cultures of Asia, where the patient depends on the family to make decisions about treatment. But, every individual would favour a peaceful death when enquired, without being burden some of the family.

\section{Autonomy Versus Ethics of Care}

The concept of Advance Directives supports the principle of Autonomy, that an individual has a right to decide for oneself. According to (Winzelberg. et. al, 2005) improving decision making at the end of life places importance on the principle of patient's autonomy, where care should be according to the individual's preferences. On the other hand the theory of Care Ethics is also dominant here, which believes in providing care and saving life. The loved ones put all their effort and resources for the recovery of their patient. Loved ones make sacrifices to provide care, and attain pride and satisfaction from protecting their relative. (Haley et. al, 2001). This theory will accuse people for being cruel if they support withholding treatment. In controversy the Basis of Care Ethics can be used to alleviate suffering of the loved ones and may encourage loved ones to favour withholding treatment. In addition to this care ethics is usually valued in intimate relationships and is not based on any moral principle (Beauchamp and Childress, 2011). Significantly, the principle of Autonomy carries a greater moral and ethical value.

\section{Arguments, Counter Arguments and Justifications}

Considering the above statements, there is really a need for a policy of Advance Directives, but awareness needs to be created. If we argue, unnecessarily prolonging life would mean pain and misery for the patient and undue expenses for the family. On the contrary what about the duty of the physician to treat conditions that could be potentially treatable (Akhtar, 2010)? But, end of life treatments can be futile and fail to improve quality of life and leave the patient miserable (Shalev, 2010). Physicians should bravely deny giving futile treatments because they can be harmful and inhumane (Kelly, 2005). Again, futility and quality of life remain questionable. Many physicians are uncomfortable and incompetent discussing about end of life issues with patients and their family. Opposing this statement, if physicians would avoid such situations, they would deny the opportunities to formulate proficient and personal ways to deal with such issues (Sorensen. \& Ledema, 2011). So, they should address these neglected issues and learn new ways of communication and skills by successive encounters. One other concern of physicians is about the uncertainty of treatment outcomes in patients who are terminally ill. Formulating criteria about which patients would benefit most from intensive care would help physicians decide treatment for these serious patients and indicate physicians when to limit treatment, and move from curative to comfort care (Sorensen. \& Ledema, 201 1). This debate shall continue in the years to come.

\section{Final Position}

Debating on this issue, and in view of all the arguments discussed, it gives us all the more reason to talk about Advance Directives with an individual, where one will be autonomous in deciding for advance treatment options for one self. This will not be a one time activity, but would need more than one meeting to understand this new concept. By having the Advance Directive, it would make easier for the health professionals to plan treatment according to the 
document of the patient, with no doubts about the comprehensiveness of the treatment. It would be the autonomous decision of the patient, which would be respected and would in turn to create a relationship of trust between the patient and the treating physician (Akhtar, 2010). The family would be saved from going through a guilt trip and it would prevent the family from unnecessary medical expenses. Health professionals should acknowledge that there would be limitations to the implementation of Advance Directives and its complexities will surface every now and then, but doing it in good spirit and an open mind would make it easier for them to communicate with individuals and family members about their end of life care preferences (Abadir, P.M. et. al, 201 1).

\section{Recommendations}

To make this Advance Directive Document workable, recommendations on the part of hospital management are to strategically involve professionals taking care of terminally ill, including physicians, anaesthetists, nurses in developing a policy. Feedback from patients and families would be useful in this regard. Awareness sessions for the users should be conducted to disseminate information, which would clarify the concept and answer questions brought up by the professionals involved. Review of the policy on a yearly basis would make it more practical. The Advance Directive Document should be custom made and should reflect the values and wishes of an individual. It should be completed in the presence of the family in a family oriented society like ours. Individuals should be helped to think and express the relation between the prognosis of a condition and their desire for life sustaining treatment.

\section{Conclusion}

The concept of Advance Directives may although seem blunt, but is realistic and can be applicable in Asian countries as well. Implementation of the policy and practices related to the concept can be evaluated at a later stage by a survey from the patients and the general public at large. Primarily this issue might not achieve recognition, but gradually with understanding it would be accepted. At least people who are in favour of Advance Directives will be able to utilize and benefit from it.

\section{References}

[1]. Abadir, P. M., Finucane, T. E., \& McNabney, M. K. (2011). When Doctors and Daughters Disagree: Twenty-Two Days and Two Blinks of an Eye. Journal of the American Geriatrics Society, 59(12), 2337-2340.

[2]. Akhtar, J., (2010). Living Wills in Health care: A way of empowering individuals. Journal of Pakistan Medical Association. 60 (3). 240-242.

[3]. Beauchamp, T.L, \& Childress, J.F. (2001). Principles of Biomedical Ethics (5thed.). New York: Oxford University Press.

[4]. Burkhardt, M. \& Nathaniel, A. (2002). Ethics \& Issues in Contemporary Nursing (2nded.). Australia: Delmar.

[5]. Haley, W.E., LaMonde, L.A., Han, B., Narramore, S., \& Schonwetter, R. (2001). Family caregiving in hospice: Effects on psychological and health functioning in spousal caregivers for patients with lung cancer or dementia. The Hospice Journal, 15, (1-18).

[6]. Kelly, J. (2005). When medical technology intrudes on humanity. World of Irish Nursing \& Midwifery, 13(7), 27-27.

[7]. Shalev, C. (2010). Reclaiming the patient's voice and spirit in dying: an insight from Israel. Bioethics, 24(3), 134144.

[8]. Sorensen, R. \& ledema, R. (2011). End-of-Life Care in an Acute Care Hospital: Linking Policy and Practice. Death Studies, 35(6), 481-503.

[9]. Winzelberg, G.S., Hanson, L.C., \& Tulsky, J.A. (2005). Beyond Autonomy: Diversifying end-of-life decision making approaches to serve patients and families. Journal of the American Geriatrics Society, 53(6), 1046-1050. 


\section{ABOUT THE AUTHOR}

Nasreen Panjwani is currently pursuing her MScN from the Aga Khan University School of Nursing and Midwifery, Pakistan. She has seven years of experience as a Faculty at the Aga Khan University School of Nursing and Midwifery, Pakistan and four years experience in Critical care areas of the Aga Khan Hospital. Her interest includes teaching in the health care field and participate in research and publications. 